\section{'NuMex Silhouette' Onion}

\author{
Christopher S. Cramer ${ }^{1,2}$ \\ Department of Plant and Environmental Sciences, Box 30003, MSC 3Q, New \\ Mexico State University, Las Cruces, NM 88003-0003
}

Additional index words. Allium cepa, open-pollinated, pink root resistance, short-day, singlecentered bulbs

The New Mexico State University (NMSU) Agricultural Experiment Station announces the release of 'NuMex Silhouette' onion (Allium cepa L.). 'NuMex Silhouette' is an open-pollinated, late-maturing, short-day, onion cultivar with red-colored dry outer scales for autumn sowing in southern New Mexico and similar environments. 'NuMex Silhouette' matures in early to mid-June when autumn-sown in Las Cruces, NM.

\section{Origin}

'NuMex Silhouette' originates from similar germplasm that was used in the development of 'NuMex Crimson' before 1989 (Cramer and Corgan, 2003) (Fig. 1). 'NuMex Crimson' is a short-day, overwintered cultivar with red-colored dry outer scales that originated from intercrosses among short-day cultivars (Kurenai, Red Grano, and Rojo) with red-colored dry outer scales, short-day cultivars (Henry's Special and Texas Grano 502 PRR) with yellow-colored dry outer scales, and an intermediate-day cultivar (Peckham Yellow Sweet Spanish) with yellow-colored dry outer scales (Cramer and Corgan, 2003). The plants of 'Texas Grano 502 PRR' had been selected for bolting resistance, labeled as NMSU 89-78-2, and used in the development of 'NuMex Silhouette'.

In Aug. 1989, seeds of NMSU 89-78-2 were sown and in January, plants that exhibited red outer scale layers (The Royal Horticultural Society Color Chart 71A) were selected and placed in a crossing cage, 90-52. In May 1990, plants in the cage flowered, pollinators were placed in the cage, and once mature, seeds were harvested from all plants in the cage. In Sept. 1990, seeds of 90-52 were sown and bulbs that possessed redcolored dry outer scales, greater bulb height and size, and fewer symptoms of pink root [causal organism, Phoma terrestris (Hansen)] were selected in May 1991. Bulbs were separated, based on their maturity, mid-May or late May. After selected bulbs broke dormancy in Oct. 1991, they were placed

Received for publication 30 Oct. 2018. Accepted for publication 1 Dec. 2018.

This research was funded by the New Mexico Agricultural Experiment Station and the New Mexico Dry Onion Commission.

${ }^{1}$ Professor of Horticulture.

${ }^{2}$ Corresponding author. E-mail: cscramer@nmsu. edu. into separate crossing cages numbered 92-10 and $92-12$, based on their relative bulb maturity (Fig. 1). In May 1992, plants in both cages flowered and seeds were harvested. In Sept. 1992, seeds of both breeding lines were sown, and bulbs that possessed red-colored dry outer scales, fewer pink root symptoms, and early (92-10) or later (92-12) maturity were selected in May 1993. After selected bulbs from each line broke dormancy in Oct. 1993, they were placed into separate crossing cages numbered 94-4 and 94-6 and in May 1994, plants in both cages flowered and seeds were harvested. In August of 1994, seeds of both breeding lines were sown, and bulbs that possessed red-colored dry outer scales, greater bulb firmness when hand squeezed, fewer pink root symptoms, and less taper toward the bottom of the bulb were selected from both lines in May (94-4) or June (94-6) 1995. In addition, bulbs with the absence of multiple meristem centers visible in the expanded leaves were selected from both breeding lines. After the selected bulbs broke dormancy in Oct. 1995, bulbs from 94-4 and 94-6 that were selected for a reduced number of visible meristems were placed as the first entry (-1) in the crossing cage, 96-6-1 and 969-1, respectively (Fig. 1). Those bulbs selected from 94-4 and 94-6 that displayed multiple meristem centers were placed as the second entry (-2) in the same respective crossing cage. In May 1996, bulbs of each entry in each cage flowered, pollinators were introduced, and once mature, seeds were harvested and kept separate from plants of each entry of each cage. In Sept. 1996, seeds of 96-61 and 96-9-1 were sown and bulbs that possessed darker red (The Royal Horticultural Society Color Chart 71A) dry outer scale layers, less pink root, and the absence of multiple meristems visible in the expanded leaves were selected in May (96-6-1) or June (96-9-1) 1997. Once the bulbs broke dormancy in Oct. 1997, the bulbs selected from 96-6-1 were placed in a crossing cage numbered $98-16$, whereas bulbs selected from 96-9-1 were placed in a crossing cage numbered 98-17-1. In May 1998, bulbs in each cage flowered, pollinators were introduced, and once mature, seeds were harvested from plants in each cage.

In Sept. 1998, seeds of 98-16 and 98-17-1 were sown and bulbs that possessed darker red dry outer and internal fleshy scale layers, less pink root symptoms, more rounded bulb shape and less taper at the bottom of the bulb, and greater bulb firmness when hand squeezed were selected from both breeding lines in June 1999. Once bulbs broke dormancy in Oct. 1999, two cycles of S1 progeny selection was initiated in which selected bulbs were placed individually in separate isolation cages to allow for selfpollination to occur the following year. Individual bulbs were selected that possessed darker red dry outer scale layers and more rounded bulb shape. In May 2000, bulbs from 33 separate cages flowered, pollinators were introduced, and seeds were harvested separately from each cage. In May or June 2001 bulbs were selected from five different breeding lines and were placed into 10 separate cages in Oct. 2001 (Fig. 1). Seeds from these cages were sown Sept. 2002 and in June 2003 bulbs were selected from nine different breeding lines (Fig. 1). In Oct. 2003, 135 selected bulbs were placed together in a single crossing cage numbered 04-10. In addition, three bulbs selected from 02-157-1 were placed in a crossing cage numbered 04215-1. In May 2004, bulbs in both cages flowered, pollinators were introduced, and seed was harvested. In Sept. 2004, seeds of both lines were sown and in June 2005, 18 bulbs total from both lines that possessed darker red dry outer and internal fleshy scale layers, greater bulb firmness when hand squeezed, and a rounder bulb shape were selected (Fig. 1). In Oct. 2005, the selected bulbs from both lines were placed together in a single crossing cage numbered 06-10.

Three additional cycles of phenotypic recurrent selection were conducted in 2006, 2008, and 2010. Bulbs were selected for a more rounded and uniform shape, increased bulb firmness when hand squeezed, fewer pink root symptoms, and darker red-colored dry outer scales. In June 2011, bulbs were selected from 10-19 for the same characteristics; and successively, in Oct. 2011, single bulbs were placed into 23 separate, small isolation cages for self-pollination, with 12 109 being one of those cages. In May 2012, bulbs in all cages flowered, pollinators were introduced, and seed was harvested. In Sept. 2012, seeds of 23 lines were sown and in June 2013 , bulbs of each line were evaluated for the same characteristics and all bulbs of 12109 were selected without making an individual bulb selection. In Oct. 2013, these bulbs were placed in a crossing cage numbered 14-09. In May 2014, bulbs flowered, pollinators were introduced, and seed was harvested and labeled as 'NuMex Silhouette'.

\section{Evaluation Procedures}

'NuMex Silhouette' was compared with 'Mata Hari' (BASF, Parma, ID), a commercial short-day, hybrid red onion cultivar, in replicated trials grown in four fields in the Mesilla Valley of New Mexico (Table 1). The field soil texture at the NMSU Fabian Garcia Science Center (trial 3) in Las Cruces, NM, was a Glendale loam, whereas the field soil texture at the NMSU Leyendecker Plant Science Research Center (trial 1), $14.5 \mathrm{~km}$ south of Las Cruces, NM, was an Armijo loam. Two trials were conducted in a 


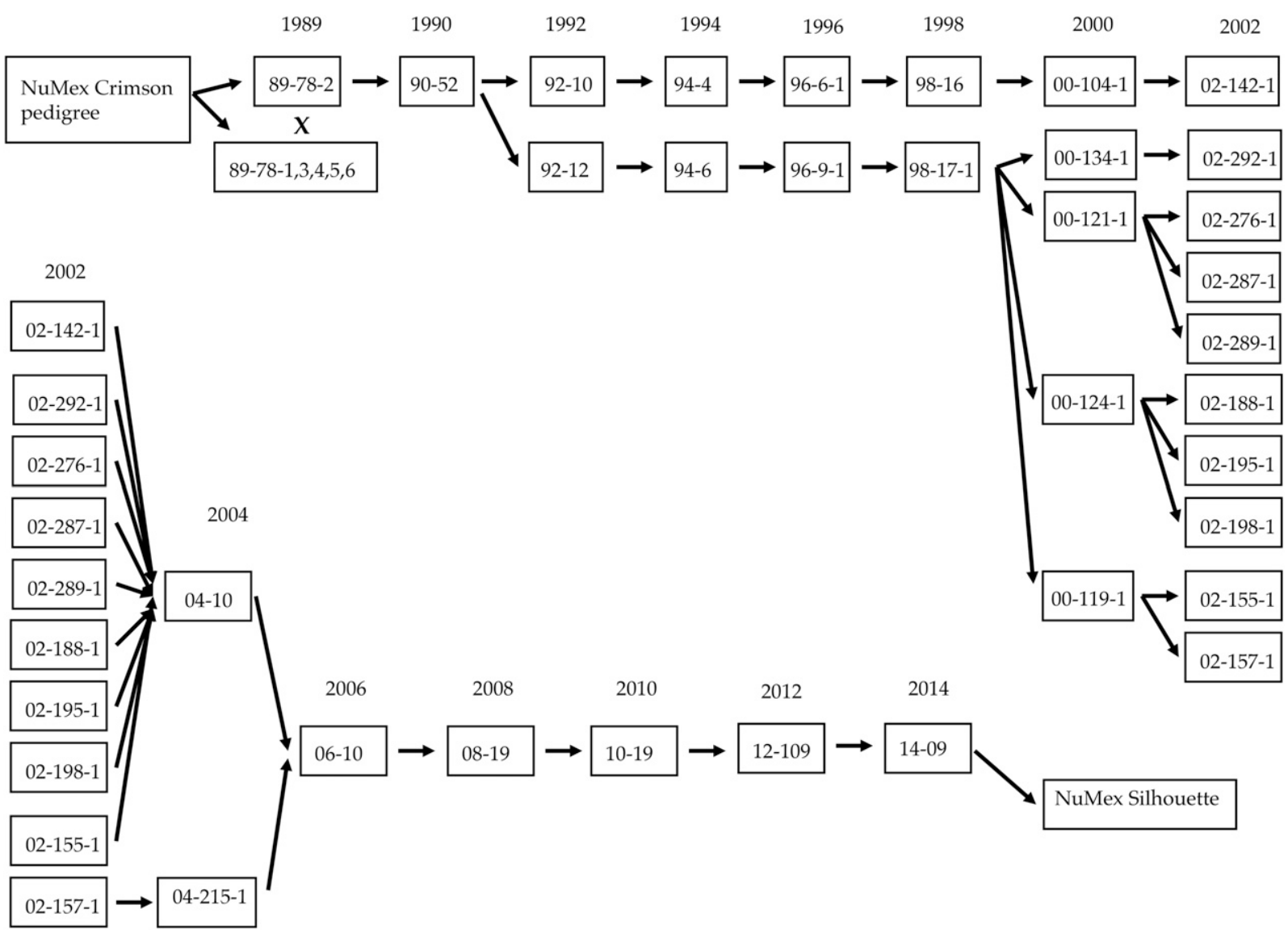

Fig. 1. Pedigree of 'NuMex Silhouette'.

Table 1. Bulb maturity, scape production, pink root severity rating, marketable yield, average bulb weight, and percentage of single centers of 'NuMex Silhouette' as compared with 'Mata Hari' when grown in Las Cruces, NM, from 2015 to 2016 and 2016 to 2017.

\begin{tabular}{|c|c|c|c|c|c|c|}
\hline Entry & Maturity date (DAS) & Scapes $(\%)^{y}$ & Pink root severity rating ${ }^{\mathrm{x}}$ & Marketable yield $\left(\mathrm{t} \cdot \mathrm{ha}^{-1}\right)^{\mathrm{w}}$ & Avg bulb wt $(\mathrm{g})^{\mathrm{v}}$ & Single centers $(\%)^{4}$ \\
\hline & & & \multicolumn{4}{|c|}{ Trial 1 (19 Oct. 2015 sowing date) } \\
\hline Mata Hari & 8 June (233) & 0.0 & 2.4 & 45.5 & 184 & 27.0 \\
\hline \multicolumn{7}{|c|}{ Trial 2 (29 Sept. 2015 sowing date) } \\
\hline NuMex Silhouette & 1 June (246) & 0.0 & 1.0 & 90.3 & 366 & 72.0 \\
\hline Mata Hari & 21 May (235) & $\begin{array}{l}2.1 \\
+\end{array}$ & $\begin{array}{l}1.0 \\
\mathrm{NS}\end{array}$ & $\begin{array}{c}100.8 \\
\text { NS }\end{array}$ & $\begin{array}{c}205 \\
\text { NS }\end{array}$ & $\begin{array}{c}46.0 \\
*\end{array}$ \\
\hline Mata Hari & 16 May (230) & 22.4 & 4.5 & 19.5 & 128 & 95.0 \\
\hline & *** & + & Trial 4 (7 Oct. 2016 sowing date) & g date) & NS & NS \\
\hline NuMex Silhouette & 5 June (250) & 0.2 & 1.0 & 116.8 & 342 & 82.0 \\
\hline Mata Hari & 30 May (244) & 2.6 & 1.0 & 142.3 & 305 & 24.0 \\
\hline & $* * *$ & NS & NS & ** & NS & $* * *$ \\
\hline
\end{tabular}

${ }^{\mathrm{z}} \mathrm{A}$ plot was considered mature when $80 \%$ of the tops were down and was harvested at that time.

${ }^{\mathrm{y}}$ The percentage of premature flower scapes was determined at harvest and calculated by dividing the number of plants with scapes by the total number of plants per plot and multiply by 100 .

${ }^{\mathrm{x}}$ Root systems of 20 bulbs per plot were rated based on a scale of 1 (no infected roots) to 9 (completely infected roots).

${ }^{\mathrm{w}}$ Marketable bulb yield ( $\mathrm{t} \cdot \mathrm{ha}^{-1}$ ) was calculated by weighing the marketable bulbs per plot and adjusting the plot size to 1 ha.

${ }^{\mathrm{v}}$ Average bulb weight was calculated by dividing the marketable bulb weight by the number of marketable bulbs.

${ }^{\mathrm{u}}$ The percentage of bulbs with single centers (single growing points) was determined by cutting each bulb transversely at the vertical center and measuring the number of growing points that extended $1.3 \mathrm{~cm}$ beyond the bulb's center.

${ }^{\mathrm{t}}$ Drip irrigation was used for trial 3 whereas furrow flood irrigation was used for trials 1,2 , and 4 .

NS, $+, *, * *, * * *$ Not significant at $P=0.10$; significant at $P=0.10, P=0.05, P=0.01$, and $P=0.001$, respectively. Test was conducted at $\alpha=0.05$.

DAS $=$ days after sowing.

grower's field. The soil texture of the grower's field used in 2015 to 2016 (trial 2, located $7.2 \mathrm{~km}$ southwest of Las Cruces) was a Glendale loam while the soil texture of the grower's field used in 2016 to 2017 (trial 4, located $4 \mathrm{~km}$ southwest of Las Cruces) was an Anthony-Vinton clay loam. Seeds were sown $\approx 1.5 \mathrm{~cm}$ deep in two rows $6 \mathrm{~cm}$ apart from late September to mid-October, depending on field location and year. For each tworow plot, $1.0 \mathrm{~g}$ of seed was sown and plants were thinned to $10 \mathrm{~cm}$ between plants within 


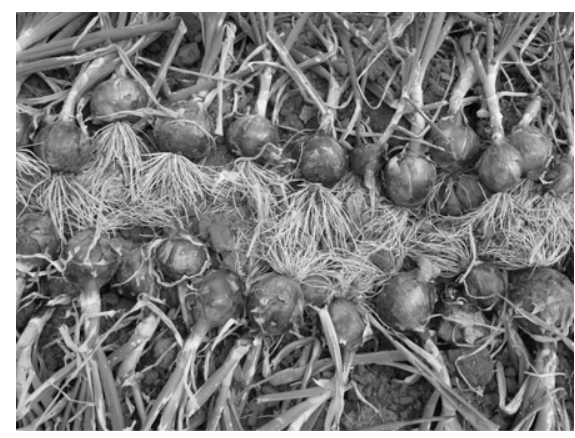

Fig. 2. 'NuMex Silhouette' onion bulbs.

the row. Each plot was $4 \mathrm{~m}$ long and $1 \mathrm{~m}$ wide and separated by an alley of $0.6 \mathrm{~m}$ from the next plot on the same bed. The trials were conducted as part of a randomized complete block design with four replications in which there were other entries not reported here. Standard cultural practices to produce autumnsown onions in southern New Mexico were followed (Walker et al., 2009). Furrow flood irrigation was used for trials 1,2 , and 4, whereas drip irrigation was used for trial 3 . Subsurface drip irrigation lines (T Tape; TSystems International, San Diego, CA) that had emitters every $20 \mathrm{~cm}$ were placed $10 \mathrm{~cm}$ deep in the center of each bed. Irrigation was applied as needed. A urea-based liquid fertilizer $(26 \mathrm{~N}-0 \mathrm{P}-0 \mathrm{~K}-6 \mathrm{~S}$; Western Blend, Inc., Las Cruces, NM) was applied as needed for trial 1 , whereas a fish fertilizer $(2.2 \mathrm{~N}-4.4 \mathrm{P}$ $0.3 \mathrm{~K}-0.2 \mathrm{~S}$; Neptune's Harvest Fertilizer, Gloucester, MA) was applied as needed for trial 3. Irrigation and fertilization for trials 2 and 4 were managed by the individual growing the cultivar that occupied the rest of the field.

Before harvest, the number of premature flower scapes was counted for each plot. From this number, the percentage of seedstalks was determined based on the total number of plants in the plot. Each plot was harvested when $80 \%$ of the plants in the plot had lodged. The harvest date was considered the maturity date, and the days from sowing until harvest were counted for each plot. The root systems of 20 bulbs from each plot were rated for the severity of pink root symptoms on a scale of 1 (no infected roots) to 9 (completely infected roots). After rating, bulbs were placed in mesh sacks and, on the same day, transferred indoors to an onion shed. Bulbs were cured for 3 to $4 \mathrm{~d}$ under ambient conditions to reduce storage losses and decay. After curing, the total bulb fresh weight was measured for each plot. Bulbs were graded to remove culls (diseased bulbs, bulbs less than $3.8 \mathrm{~cm}$ in diameter, split and double bulbs). The number of culls was subtracted from the total bulb number to obtain the marketable bulb number per plot. After bulbs were graded, they were weighed again to obtain marketable bulb weight per plot. The average bulb weight was calculated by dividing marketable bulb weight by marketable bulb number. After grading, 25 bulbs were cut transversely at the widest point on the vertical axis to determine the percent of bulbs possessing a single meristem. If a bulb possessed a single meristem or multiple meristems within $1.3 \mathrm{~cm}$ of the bulb center, then the bulb was considered single-centered. A $t$ test [SAS statistical software (SAS Institute, Cary, NC, version 9.4)] was used to determine differences between means of 'NuMex Silhouette' and 'Mata Hari' for each trait.

\section{Description and Performance}

'NuMex Silhouette' (Fig. 2) is a latematuring, short-day, open-pollinated, globeshaped onion with red-colored dry outer scales that matures from 1 to 23 June when autumn-sown in Las Cruces, NM (Table 1). Suggested planting dates at Las Cruces are 25 Sept. to 10 Oct. Bulbs of 'NuMex Silhouette' mature 6 to $28 \mathrm{~d}$ later than bulbs of 'Mata Hari' (Table 1). This later maturity will allow for continuity of harvest of red onions. When conditions were conducive for premature seedstalk formation, bulbs of 'NuMex Silhouette' exhibited a lower percentage of scapes (seedstalks) than bulbs of 'Mata Hari'
(Table 1). Bulbs of 'NuMex Silhouette' exhibited a comparable or reduced amount of pink root symptoms when compared with bulbs of 'Mata Hari' (Table 1). Two trials exhibited no incidence of pink root disease because the causal organism was not present in these fields. This lack of pink root also impacted marketable bulb yield and bulb weight. Both of these traits were greater in trials 2 and 4 , where no pink root was observed, than in trials 1 and 3, where the pink root incidence was greater. Typically, fields that have no previous history of onion cultivation exhibit a low pink root incidence, whereas fields used previously for onion cultivation have a greater incidence of pink root. Even with differences between trials in average marketable bulb yield and bulb weight, both were comparable between 'NuMex Silhouette' and 'Mata Hari' (Table 1). The percentage of single-centered bulbs produced by a red onion bulb cultivar is desirable for visual display when the bulb is cut transversely. The percentage of single-centered bulbs is often a function of bulb size, as smaller bulbs tend to have fewer elongated meristems whereas larger bulbs tend to have more. When larger bulbs were produced, 'NuMex Silhouette' produced a greater percentage of single-centered bulbs than 'Mata Hari', even though the average bulb size was similar between both cultivars (Table 1).

\section{Availability}

Interested parties should contact Kathryn Hansen, Arrowhead Center, MSC 700, Box 30001, New Mexico State University, Las Cruces, NM 88003-8001, 575-646-4220, hansen@ad.nmsu.edu, with regard to obtaining seed samples.

\section{Literature Cited}

Cramer, C.S. and J.N. Corgan. 2003. 'NuMex Crimson' onion. HortScience 38:306-307.

Walker, S., J. Ashigh, C.S. Cramer, T. Sammis, and B. Lewis. 2009. Bulb onion culture management for southern New Mexico. New Mexico Coop. Ext. Serv. Circ. 563, 16 pp. 